expert) clinical assessment of patient came to Child and Youth protection Center, Zagreb, Croatia, in case of adverse childhood experiences, acording ACEs (Adverse Childhood Experience score) $\geq 4$. From 2015 - 2019 in Child and Youth Protection Center Zagreb we prospectively observed 1053 children with $\geq 4$. We were looking for presence of minor neurological dysfunctions (gross motor function, mild dysfunction in posture, reflexes, coordination, fine manipulative ability, fine motor disfunction, dyskinesia and excessive associated movements). For those with ACES $\geq 4$, and neurodevelopmental delay, EEG was indicated. We also evaluated simptoms of impulsivity, hyperactivity, and an inability to focus.

Neglect, physical and emotional abuse and high conflict divorce are the most important adverse experiences resulting in deviations in neurodevelopment.

Impulsive behaviour, and other form of ADHD 'like' variants are significantly more frequent (over 50\%) in children with history of some kind of abuse or neglect. Over $70 \%$ of patients with ACES $\geq 4$ showed dysrhytmic or other form of nonspecific changes in EEG.

In order to understand better the processes of the effects of toxic stress on the developing brain and identify forms of intervention, we have to apply several levels of study - scientific and theoretical, empirical and professional. An integrative paradigm in an approach to neurodevelopmental disorders caused by negative environmental factors provides the conceptual framework for further insight.

\section{THE INTEGRATION OF CHILDREN AND ADOLESCENTS WITH DEVELOPMENTAL DISABILITIES}

Željka Karin* ${ }^{*}$ Tonka Karin. Public Health Institute of Split and Dalmatian County

10.1136/archdischild-2021-europaediatrics.460

Introduction In Croatia, any child having developmental disabilities with an essential need of school educational support is entitled to accessibility and inclusion in order to be provided with free primary and high school education. A psychosomatic disorder in child is determined by the specialist of school and adolescent medicine who along with the team of school expert associates (psychologist, pedagogue, defectologist) is responsible for ensuring an adequate form of school education and support for the eligible child.

Within his activities at the primary level of healthcare in the public health system, the school doctor continuously monitors health condition and abilities in children and adolescents, the implementation of therapeutic, rehabilitation and other professional practices as well as the school education adjustment meeting the needs of persons with health disabilities.

The Aim To present the results of the psychosomatic assessment in children as well as to determine the adequate programme of the elementary and high school education for school children with developmental disabilities. To report on most common disabilities affecting the educational attainment and functioning in school children.

The subjects and methods: By using retrospective data analysis of the annual reports comprising 172 school medicine teams in the Republic of Croatia from the elementary and high school children, the proportion of children who due to developmental disabilities were provided with an adequate school education programme, was determined. In children with disabilities an adequate form of school education was determined by gender and school, as well as most common disabilities affecting educational attainments.

The results: When establishing psychosomatic condition in children due to developmental disabilities for 5.2\% of elementary school children and $1 \%$ of high school children, one of the school education forms was determined. In relation to school children provided with the adequate form of school education in elementary school 37\% girls followed regular programme with an individual approach, 49\% girls were provided with an individual approach and adjusted programme, $6 \%$ girls with a special programme, whereas $8 \%$ girls were in the programme for acquiring competences. Within regular programme an individual approach in school education was provided for $45 \%$ elementary school boys, an individual approach and adjusted programme for $41 \%$ boys, a special programme for $5 \%$ boys, and in the programme for acquiring competences there were $9 \%$ boys. In high school within the regular programme, an individual approach was provided for $41 \%$ females and 39\% males, an individual approach and adjusted programme were followed by $21 \%$ females and $20 \%$ males, special programme was provided for $11 \%$ females and $13 \%$ males, whereas in the programme for acquiring competences and individual approach were $27 \%$ females and $28 \%$ males.

In children provided with an adequate form of school education most common diagnoses according to DSM-10 classification affecting school attainments and functioning of children related to voice and speech disorder as well as specific learning difficulties in $37.9 \%$, central nervous system impairment in $20.7 \%$, mental disorder and behaviour disorder in $19.5 \%$, and intellectual disabilities in $14.2 \%$ children.

The conclusion: The school child with developmental disabilities requires educational support and education mandatory for all children having developmental disabilities in order to enable positive health-related and educational outcomes along with maintaining and promoting physical and mental health. In order to facilitate school education of children with developmental disabilities and to promote developmental potentials in children, a multidisciplinary approach is essential to make disability assessment in children, to estimate their abilities and capacities as well as to determine developmentally appropriate education and support.

\section{HOW CAREGIVER'S HOSPITAL CONSULTATION TIMING IS INFLUENCED BY THE CARE TARGET II -IN CASE OF ASD, ADHD, ALLERGIC OR OTHER DISEASES}

Juri Ogawa*, H Tajima*, M Kakinuma*, M Takarabe*, Y Momota, I Nose, M Takahashi. Nippon Medical School

\subsection{6/archdischild-2021-europaediatrics.461}

The timing of consulting the hospital is important to ensure the quality of life of the child. Avoiding the delay in consulting is very important as well avoiding unnecessary visit. Based on the study with veterinary study on visitation timing, we speculate that caregivers may not be making the judgement purely on child's physical condition, but basing on the expression of the pain or difficulties of taking the child to the hospital. Therefore, it is important to understand how disease, disabilities specific behavior of the child influences the hospital consultation timings or frequencies by the caregiver. If the consultation timings are influenced by child's behavior, or characteristics, preventive education would be possible for the 
caregivers for proper timing for taking the child to the hospital, to avoid being too late or unnecessary visitation.

Survey is conducted to pediatricians about school age children with ASD, ADHD, Down Syndrome, Epilepsy, Premature baby and Allergy. Questions include about reactivity to pain, expression of pain, behavior at the hospital (obedient or not) and the timing of consultation. Pediatricians are asked to rate them in comparison to typically developing children.

Caregiver's hospital consultation patterns differed according to the difficulties children had. While children with ASD and ADHD tend to react to pain much, had trouble waiting at the hospital, and do not consult at early state, premature born children react to pain as typically developing children, do not have trouble waiting at the hospital and tend to consult hospital at early state, possibly unnecessarily.

The results suggest that caregivers are making consultation judgment based on the child's expression pain as well as their behavior at the hospital.

Based on these findings, it would be possible to create guidelines based on the child's characteristics so that caregivers can make more appropriate judgment for when to consult the hospital.

\section{HOW CAREGIVER'S HOSPITAL CONSULTATION TIMING IS INFLUENCED BY THE CARE TARGET I -IN CASE OF VETERINARY VISITS}

Miki Kakinuma*, M Takarabe, Y Momota, H Tajima, J Ogawa, I Nose, M Takahashi.

\subsection{6/archdischild-2021-europaediatrics.462}

Pediatrics and veterinary medicine are often compared for the timing of hospital consultation is not based on the patient himself, but the caregiver. In case of human patient and the caregiver, often biologically related, the delay or unnecessary visit to the hospital may be blamed to caregiver's characteristics. For example, if the mother is nervous, then the child becomes nervous or if the mother is indifferent, then the child do not express pain. In case of veterinary medicine, the owner and the dog are not biologically related, but there are nervous owners and nervous dogs, or indifferent owners and indifferent dogs. In this study, we examine the possibility of dog's behavior making the owners nervous or indifferent.

60 small animal veterinarians in Japan are asked to rate about the owner and the 6 most popular dog breeds, Dachshund, Chihuahua, Toy Poodle, Shiba inu, mix and Shih-Tzu. Questions included the expression of pain, behavior at the waiting room, consultation time, dogs' aggression toward the veterinarian and others.

60 dog owners were asked to describe the timing of the veterinary consultation. Dogs in general do not express much pain that owners looked at other signs such as loss of appetite or not moving. Dog showed no pain in heart related diseases, and some for skin diseases.

Breed differences were observed in pain expression, ShihTzu, Dachshund and mix breeds are less reactive to pain while Chihuahua, Toy Poodle and Shiba are rated as reactive $(x 2(5)=108, p<.01)$. Chihuahua, Toy Poodle owners consult the clinic at early stage of the diseases while mix, Dachshund and Shih-Tzu do not $(x 2(5)=115 \mathrm{p}<.01)$. Even though Shiba inu express pain, it bites veterinarians, that owner tend to wait to consult the vets.

The breed differences in owner behavior of vet. consultation suggests that owners are judging the timing based on the dogs pain expression and also the difficulties they experience at the vet more than the actual condition of the diseases. Some breeds are more likely to express pain and thus making owners more nervous while others do not express pain that owners miss the proper timing for the vet. consultation. Similar pattern may be observed in pediatric consultation as well. By understanding how the care targets behave influence the caregiver's behavior of hospital consultation, more efficient preventive information specific to diseases may be provided to the caregivers.

\section{COGNITIVE FUNCTIONS AND LIFESTYLE OF RUSSIAN SCHOOLCHILDREN IN LARGE CITIES}

Georgii Karkashadze*, L Namazova-Baranova, A Molodchenkov, E Vishneva, T Gogberashvili, T Konstantinidi. Research Institute of Pediatrics and child health of the Central clinical hospital of the Russian Academy of Sciences MES

10.1136/archdischild-2021-europaediatrics.463

Goal to determine the relationship between the parameters of cognitive functions, school performance and extracurricular lifestyle.

Method: 1036 children aged 10-12 years who studied in 5th classes of 40 Russian schools in 8 different major cities were surveyed. All of them underwent cognitive testing, which included a set of six tests. They defined: arbitrary attention, visual-spatial perception, verbal memory, visual-imaginative thinking, constructive praxis, and verbal-logical thinking. Parents of 598 participants filled out questionnaires about their lifestyle. Using machine learning methods, children were divided into clusters based on the success of cognitive tests. Next, we analyzed the links between cognitively successful children, school performance, and lifestyle.

Results it was found that children are divided into two clusters: those who performed cognitive tasks more successfully and less successfully. A strong direct link was established between the success of cognitive tests and school performance in three main subjects (mathematics $(r=0.875)$, literature $(r$ $=0.853)$, and Russian $(\mathrm{r}=0.797)$. Those who spent more time using the Internet and were more interested in computer games did not differ in cognitive parameters from those who used less and played less. But those who didn't play computer games at all during school days were worse at cognitive functions. Also worse in cognitive functions were those who were interested in unorganized sports (outside of sports clubs), hockey, mountain skiing, lawn tennis, a combination of a passion for music and education with Tutors. High cognitive functions are associated with music, non-sports Hobbies, basketball, football, dancing, and summer recreation in camps.

Many lifestyle manifestations were not related to the level of cognitive function.

Conclusion Cognitive functions are strongly associated not only with school performance, but also with certain Hobbies and lifestyles of children. Such data may be interesting for social policy in the field of childhood. 